\title{
Effect of Sample Width on Flame Spread Rate over a Thin Material in Microgravity
}

\author{
By Shuhei TAKAHASHI ${ }^{1)}$, Yasunori SEKI ${ }^{1)}$, Tadayoshi IHARA ${ }^{1)}$, \\ Kazunori WAKAI $^{1)}$, and Subrata BHATATCHARJEE ${ }^{2)}$ \\ ${ }^{1)}$ Department of Mechanical and Systems Engineering, Gifu University, Gifu, Japan \\ ${ }^{2)}$ Department of Mechanical Engineering, San Diego State University, CA,USA
}

(Received April 25th, 2008)

\begin{abstract}
The effect of the sample width on the flame spread rate over a thin PMMA film in microgravity has been investigated by experiments and scale analysis. The oxygen level of the ambient gas is kept fixed at $30 \%$ while different diluents - $\mathrm{N}_{2}$, $\mathrm{Ar}, \mathrm{He}$, and $\mathrm{CO}_{2}$ - are used. The sample width is also used as a parameter, varying through $5 \mathrm{~mm}$, $10 \mathrm{~mm}$, and $20 \mathrm{~mm}$. When helium is used as the diluent, the conductive heat loss to the sides becomes large, and therefore, the flame is suppressed with a significant drop in the flame spread rate and flame size, especially at low oxygen level and for narrow sample widths. For other diluents, the radiative loss is the dominant factor for the suppression, and the sample width has small impact. These experimental findings can be explained with the scale analysis.
\end{abstract}

Key Words: Flame spread, Extinction, PMMA, Microgravity

\section{Nomenclature}

$a_{a b s} \quad$ Absorption coefficiency of gas

$c_{g} \quad$ Specific heat of gas

$c_{s} \quad$ Specific heat of solid

F Flame constant, Eq. (1)

$L_{g} \quad$ Gas-phase diffusion length scale

$L_{g x} \quad$ Gas-phase diffusion length scale in x-direction

$L_{g y} \quad$ Gas-phase diffusion length scale in y-direction

$L_{s x} \quad$ Length of the preheated solid phase

$L_{s y} \quad$ Thickness of the preheated layer

$R_{\text {loss }} \quad$ Total heat loss number, $R_{\text {loss }}=R_{\text {rad }}+R_{\text {side }}$

$R_{\text {rad }} \quad$ Radiation loss number, Eq. (2)

$R_{\text {side }} \quad$ Side loss number, Eq. (3)

$T_{f} \quad$ Characteristic (adiabatic) flame temperature

$T_{v} \quad$ Constant vaporization temperature

$T_{\infty} \quad$ Ambient temperature

$V_{g} \quad$ Ambient flow velocity

$V_{g, c r} \quad$ Critical ambient flow velocity

$V_{f} \quad$ Absolute spread rate

$V_{r} \quad$ Velocity relative to the flame, $V_{r}=V_{g}+V_{f}$

$W \quad$ Width of the fuel in z-direction

$\alpha_{g} \quad$ Thermal diffusivity of gas, evaluated at $T_{v}$

$\alpha_{s} \quad$ Thermal diffusivity of solid

$\varepsilon \quad$ Surface emissivity

$\lambda_{g} \quad$ Gas-phase conductivity evaluated at $T v$

$\lambda_{s} \quad$ Solid-phase conductivity

$\eta \quad$ Non-dimensional spread rate, Eq. (4)

$\rho_{g} \quad$ Gas density evaluated at $T v$

$\rho_{s} \quad$ Solid density

$\tau \quad$ Fuel half-thickness

\section{Introduction}

Many studies that have been carried out on flame spread phenomenon over a solid material in microgravity reveal that the flame spread is quite different from those in normal gravity especially with very slow ambient flow ${ }^{1-6)}$. In such a situation, the flame becomes very weak, and it is thought that this weakness is due to radiative heat loss ${ }^{7-9}$ ) and insufficient supply of oxygen ${ }^{10)}$. The lower the ambient flow velocity is, the larger the flame characteristic length, namely the preheat zone length, becomes. The enlarged preheat zone increases the ratio of the radiative loss to the heat conduction to the solid phase, which leads to a reduction in flame spread rate and, eventually, extinction when the conduction to the solid is insufficient to raise the fuel temperature to its vaporization temperature.

In previous publications, we have discussed the heat balance in the microgravity regime using a scale analysis, which can give insight for estimating the impact of factors that affect the spread rate, such as the ambient flow velocity, the thermal properties of the gas and the solid, the fuel geometry, and so on ${ }^{11,12)}$. In this article, we present the impact of the sample width ${ }^{13-15)}$ on the spread rate by measuring the spread rate over a thin PMMA film in microgravity while varying the ambient velocity, the diluent gas, and the width of the fuel sample.

\section{Experimental Setup}

Figure 1 shows the experimental apparatus and the set up of the interferometer to measure the spread rate and the flame scales. The volume of the closed-type wind tunnel is $7000 \mathrm{cc}$, and the cross-section of test area is $10 \mathrm{~cm}$ in height and $9.5 \mathrm{~cm}$ in width. The oxygen level is $30.0 \%$ and the pressure is $100 \mathrm{kPa}$ for all conditions. For these conditions, it can be shown that the oxygen concentration in the chamber can decrease from $30.0 \%$ to $29.3 \%$ under the most severe condition of complete combustion. The sample is a thin PMMA film whose thickness is $0.125 \mathrm{~mm}$ 
and length is $6 \mathrm{~cm}$. It is set in the test area and ignited with the electrically heated $\mathrm{Ni}-\mathrm{Cr}$ wire. The ambient flow velocity is adjusted with a fan, driven by the brush-less motor from $0 \mathrm{~cm} / \mathrm{s}$ to $28 \mathrm{~cm} / \mathrm{s}$.

To change the thermal properties of the oxidizer, we use $\mathrm{N}_{2}, \mathrm{CO}_{2}$, Ar, and $\mathrm{He}$ as diluents (see Table 1). We also selected different sample widths - $5 \mathrm{~mm}, 10 \mathrm{~mm}$ and 20 $\mathrm{mm}$ - to investigate three-dimensional effects. The flame is recorded with a CCD camera and the spread rate is measured from the video analysis afterwards. The interferometer is used to measure the pre-heat zone length in the gas phase ahead the flame. The microgravity environment is obtained with the $4.5 \mathrm{sec}$ drop tower of MGLAB in Toki City in Japan.

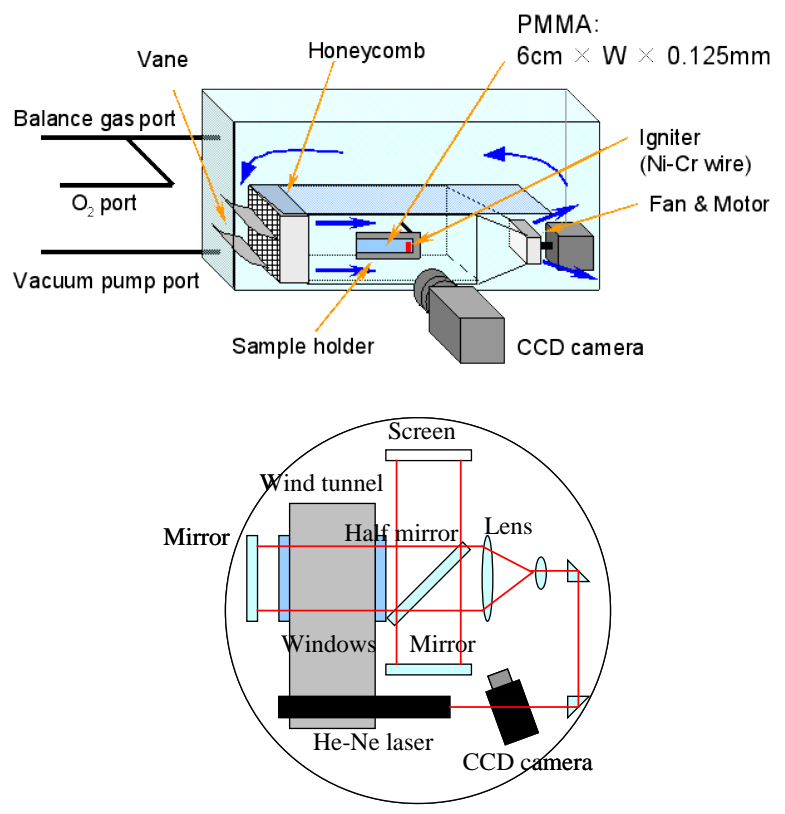

Fig. 1 Schematic of the closed-type wind tunnel for spread rate measurement and the interferometer system for flame size measurement

Table 1 Properties of diluent gases at $300 \mathrm{~K}$ and $1 \mathrm{~atm}$

\begin{tabular}{c|c|c|c|c}
\hline \hline & $\begin{array}{c}\mathrm{Cp} \\
{[\mathrm{J} / \mathrm{mol} \mathrm{K}]}\end{array}$ & $\begin{array}{c}\lambda_{\mathrm{g}} \\
{[\mathrm{W} / \mathrm{m} \mathrm{K}]}\end{array}$ & $\begin{array}{c}\alpha_{\mathrm{g}} \\
{\left[\mathrm{mm}^{2} / \mathrm{s}\right]}\end{array}$ & $\begin{array}{c}\text { Absorption } \\
\text { band }[\mu \mathrm{m}]\end{array}$ \\
\hline \hline $\mathrm{N}_{2}$ & 29.06 & 0.0249 & 21.1 & - \\
$\mathrm{CO}_{2}$ & 37.2 & 0.0164 & 10.9 & 4.4 \\
$\mathrm{He}$ & 20.78 & 0.158 & 186.6 & - \\
$\mathrm{Ar}$ & 20.78 & 0.0178 & 21.1 & - \\
\hline \hline
\end{tabular}

\section{Scale analysis}

When the dominant deriving factor is the thermal conduction from the gas-phase preheat zone to the solid-phase preheat zone, the flame spread rate can be estimated with the simple equation,

$$
V_{f, t h} \rho_{s} c_{s} L_{s y} W\left(T_{v}-T_{\infty}\right) \sim \lambda_{g} \frac{\left(T_{f}-T_{v}\right)}{L_{g y}} L_{g x} W,
$$

which yields
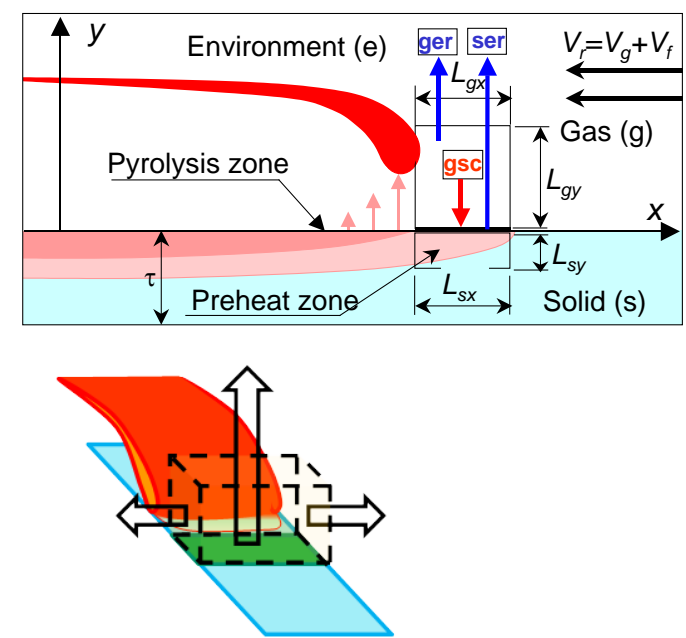

Fig. 2 Schematic of flame structure for scale analysis

$$
V_{f, t h} \sim \frac{\lambda_{g}}{\rho_{s} c_{s} \tau} F \text { where } F \equiv \frac{T_{f}-T_{v}}{T_{v}-T_{\infty}} .
$$

The above expression is identical to the de Ris's equation ${ }^{17)}$. This equation states that large thermal conductivity and high flame temperature result in large spread rate. The situation where the thermal conduction from the flame to the solid is the dominant driving force of the flame spread is so-called "thermal regime."

We now consider the heat losses due to the radiation to the surroundings from the solid preheat zone and due to the conduction to surroundings from the gas-phase preheat zone sideward through the edges (see Fig. 2).

$$
V_{f} \rho_{s} c_{s} L_{s y} W\left(T_{v}-T_{\infty}\right)+q_{\text {loss }} \sim \lambda_{g} \frac{\left(T_{f}-T_{v}\right)}{L_{g y}} L_{g x} W
$$

where

$$
\begin{aligned}
& q_{\text {loss }}=q_{\text {rad }}+q_{\text {side }} \\
& =\varepsilon\left(1-\alpha_{a b s}\right) \sigma\left(T_{v}^{4}-T_{\infty}^{4}\right) L_{s x} W+2 \lambda_{g} \frac{\left(T_{f}-T_{\infty}\right)}{W / 2} L_{g x} L_{g y}
\end{aligned}
$$

The ratios of these losses to the heat conduction from the gas phase to the solid phase to drive the flame are expressed as below; $R_{\text {rad }}$ and $R_{\text {side }}$.

$$
\begin{aligned}
& R_{\text {rad }}=\frac{\varepsilon\left(1-a_{a b s}\right) \sigma\left(T_{v}{ }^{4}-T_{\infty}{ }^{4}\right)}{\rho_{g} c_{g} V_{r}\left(T_{f}-T_{v}\right)} \propto\left(1-a_{a b s}\right) \frac{1}{V_{r}} \\
& R_{\text {side }}=4\left(\frac{\alpha_{g}}{V_{r} W}\right)^{2} \frac{T_{f}-T_{\infty}}{T_{f}-T_{v}} \propto \alpha_{g}^{2} \cdot \frac{1}{W^{2}} \frac{1}{V_{r}^{2}}\left(=\frac{L_{g}^{2}}{W^{2}}\right)
\end{aligned}
$$

Using these non-dimensional factors and the non-dimensional flame spread rate, $\eta$, the heat balance equation is reduced to the following simple equation;

$$
\eta+R_{\text {rad }}+R_{\text {side }}=1 \text { where } \eta \equiv V_{f} / V_{f, t h} \cdot
$$

This equation expresses the spread rate in "microgravity regime," and it states that the extinction occurs if the sum of $R_{\text {rad }}$ and $R_{\text {side }}$ excesses unity. The 
heat losses, $R_{\text {rad }}$ and $R_{\text {side }}$, increase with the decrease of the relative ambient flow velocity, $V_{r}$, however, the each impact on the spread rate is different. The radiative loss is proportional to the $V_{r}^{-1}$ and independent on the width, $W$, whereas side loss is to the $V_{r}^{-2}$ and depend on $W$. It is expected that side loss would overwhelm the radiative loss when the sample width is narrow and/or the thermal diffusivity of the ambient gas, $\alpha_{\mathrm{g}}$, is large. This implies that the flame becomes weak when helium is used as the diluent gas and it becomes robust if the sample width is wide.

\section{Results and Discussion}

\subsection{Flames in the thermal regime}

In order to confirm the tendency of the flame in the thermal regime, we first measure the downward spread rate in normal gravity, where the typical flame in the thermal regime was achieved. Figure 3 shows the calculated spread rate with Eq. (1) over the sample with infinite width, and the measured downward spread rate over the sample of $20 \mathrm{~mm}$ width. The oxygen level is varied as a parameter. In downward spread conditions, the buoyant flow, which can be estimated to be about $30-40 \mathrm{~cm} / \mathrm{s}$, acts as the opposing flow. Therefore, the heat loss factors, $R_{\text {rad }}$ and $R_{\text {side }}$, can be assumed to be small. Moreover, the sample width is $20 \mathrm{~mm}$ large, making $R_{\text {side }}$ relatively small. Hence, these flames are considered within the thermal regime.

In the thermal regime, therefore, we expect spread rates to be ordered for different diluents in the manner $\mathrm{He}>\mathrm{N}_{2}$ $\sim \mathrm{Ar}>\mathrm{CO}_{2}$, which is consistent to Eq. (1) and the thermal properties in Table 1 . In the He balance condition, the thermal conductivity is large and the flame temperature is also large due to small heat capacity, which leads to large spread rate. On the other hand, in the $\mathrm{CO}_{2}$ balance condition, the thermal conductivity and the flame temperature are both relatively low; therefore, the spread rate became small. The experimental results show good agreement with these predictions, confirming that flame spread in the thermal regime is achieved in downward spread at $30 \%$ oxygen level.

\subsection{Flames in the microgravity regime}

In microgravity, the ambient flow velocity around the flame can be very small. In such a condition, the flame

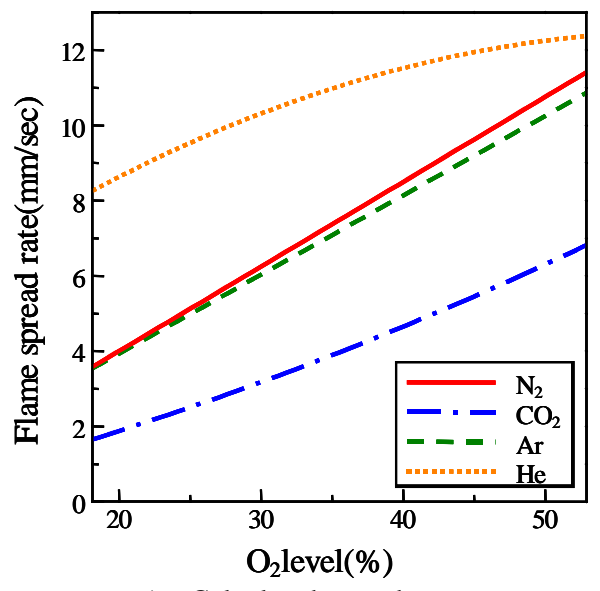

a) Calculated spread rate

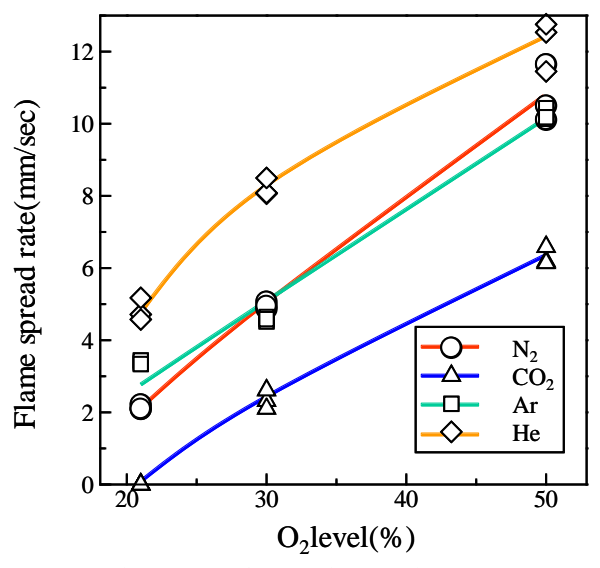

b) Experimental spread rate

Fig. 3 a) Calculated spread rate over infinite width sample with Eq. (1), and b) experimental spread rate over $20 \mathrm{~mm}$ width sample.

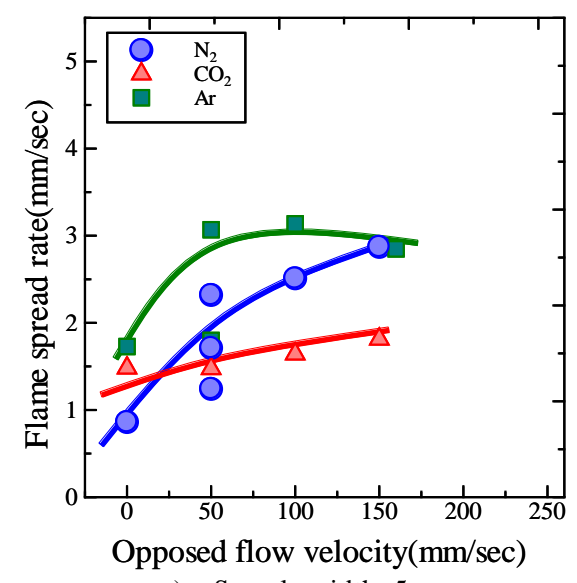

a) Sample width: $5 \mathrm{~mm}$

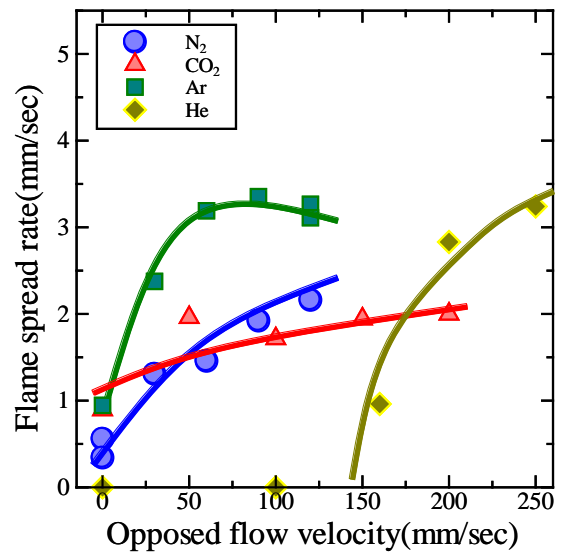

b) Sample width: $10 \mathrm{~mm}$

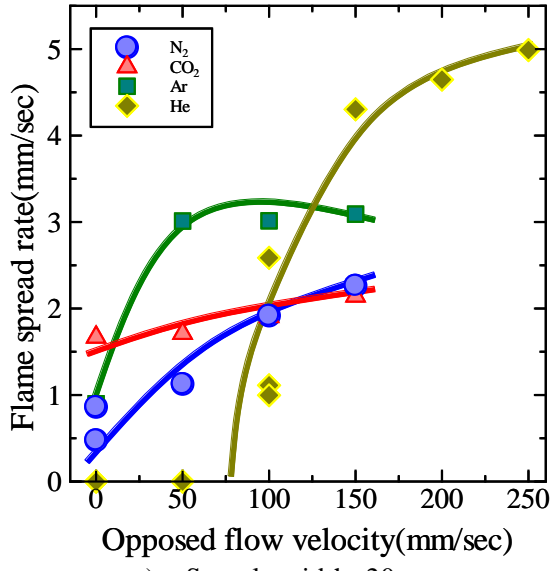

c) Sample width: $20 \mathrm{~mm}$

Fig. 4 Flame spread rate in each balance gas condition. The oxygen level is fixed at $30 \%$. The sample width is changed as a) 5mm, b) $10 \mathrm{~mm}$, and c) $20 \mathrm{~mm}$. When the $5 \mathrm{~mm}$ width sample is used, the flame spread is not observed in all He balance conditions. 
spread becomes smaller due to radiative heat loss and the conductive heat loss to the sides (three dimensional effect) as shown in Eqs. (2)-(4). Figure 4 plots the spread rate against the flow velocity for different diluents and sample width. In all conditions, the spread rate decreases when the ambient flow velocity approaches zero. This result implied that the heat loss increased neat a quiescent condition. However, the degree of suppression is dependent on the diluents and the sample width.

In the case of $\mathrm{N}_{2}$ or Ar, the flame spread rate decreases rapidly when the ambient flow velocity becomes less than $5 \mathrm{~cm} / \mathrm{s}$. On the other hand, for $\mathrm{CO}_{2}$, the spread rate is not suppressed so much in spite of low ambient flow, that is, a robust flame can be observed in a quiescent condition. With He as the diluent, flame spread cannot be observed when the ambient flow is less than $10 \mathrm{~cm} / \mathrm{s}$. This is quite a contrast from the thermal regime, where He produces the fastest spread rate under similar conditions. It was worthy to notice that the suppression in the He balance condition was very sensitive to the sample width, whereas those in the other conditions were not.

The difference of the suppression tendency among these four conditions can be explained with the scale analysis. The heat loss factors, $R_{\text {rad }}$ and $R_{\text {side }}$, are both sensitive to
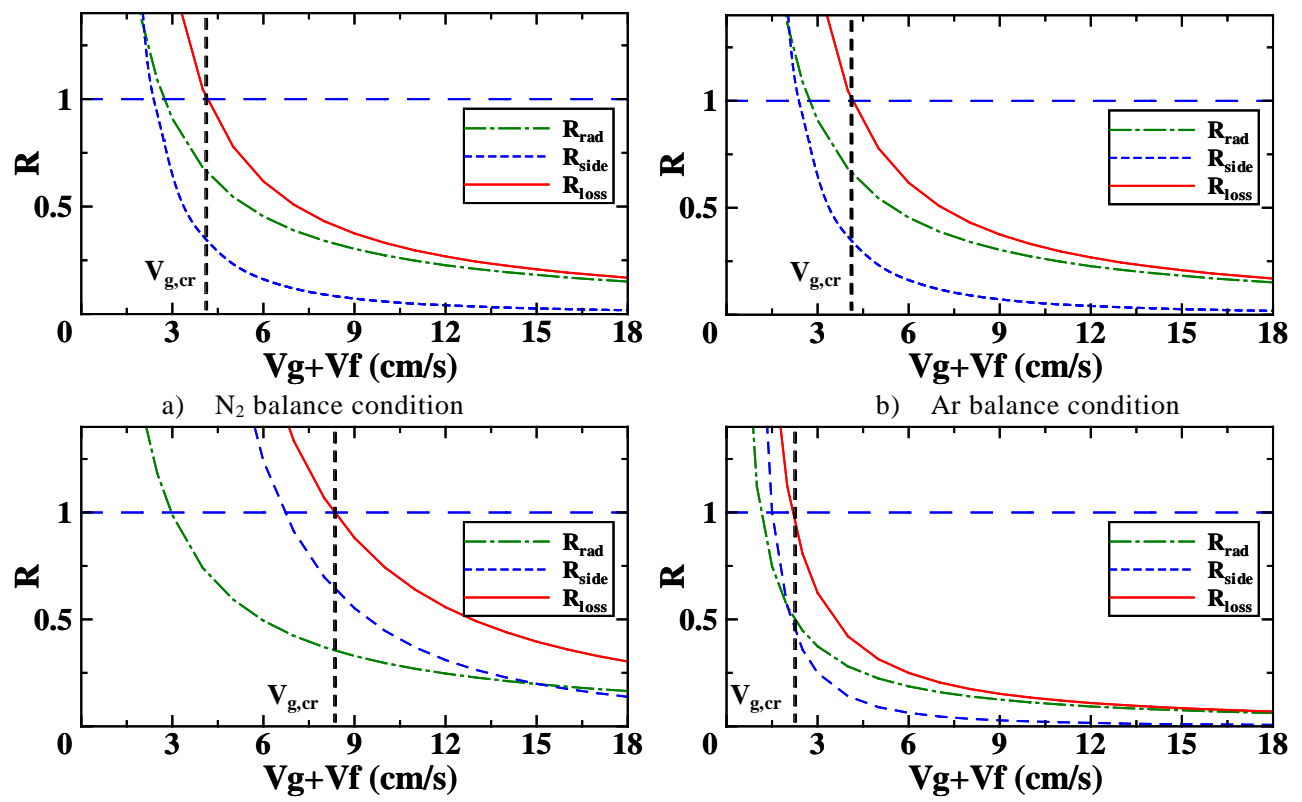

c) He balance condition

b) $\mathrm{CO}_{2}$ balance condition

Fig. 5 Non-dimensional heat loss factors with varying ambient flow velocity.

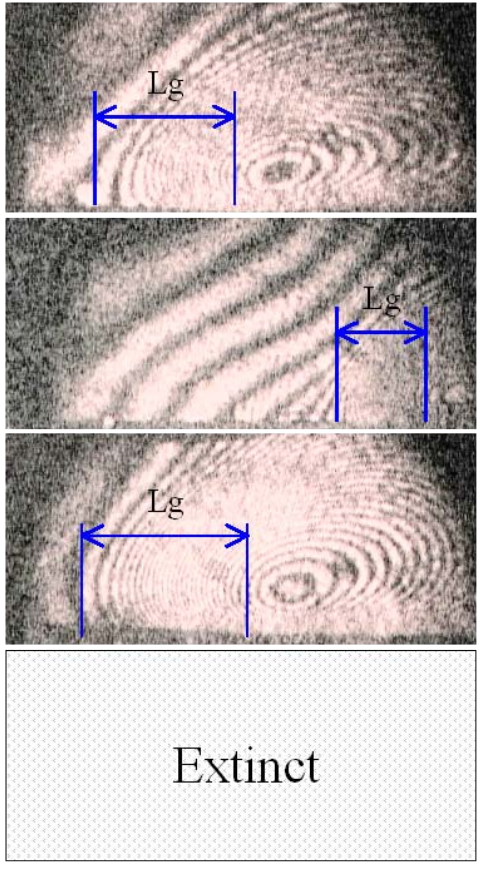

a) $V_{g}=0 \mathrm{~cm} / \mathrm{s}$

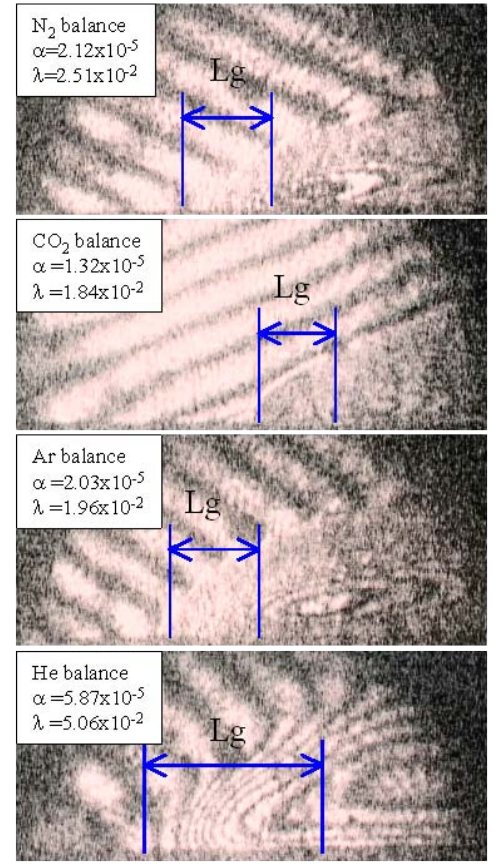

b) $V_{g}=16 \mathrm{~cm} / \mathrm{s}$

Fig. 6 Interferometer images in a quiescent condition and with a mild ambient flow. 
the relative ambient flow velocity, $V_{r}$, whereas only $R_{\text {side }}$ is affected by sample width, $W$. The high sensitivity of the experimental data (spread rate and flame size) on the width in the case of He dilution implies that the dominant heat loss path is primarily driven by sidewise heat loss. In the case of other diluents, however, it is the radiative loss which is dominant and sample width has relatively smaller effect.

Figure 5 shows the calculated heat loss factors, $R_{\text {rad }}$ and $R_{\text {side }}$, for the condition shown in Fig. 4b. When the sum of $R_{\text {rad }}$ and $R_{\text {side }}$ reaches unity at the critical ambient velocity, $V_{g, c r}$, the flame is considered to be extinct. The result shows the robust flame for $\mathrm{CO}_{2}$ in contrast to the weak flame in the case of He. The result shows not only the robustness of the flame near the quiescent condition, but also the ratio of $R_{\text {rad }}$ and $R_{\text {side, that reveals the }}$ dominant factor for the suppression. For He, the large $\mathrm{R}_{\text {side }}$ due to large thermal diffusivity results in large $V_{g, c r}$, which means weak flame in microgravity. At the critical velocity, the $R_{\text {side }}$ is about 2 times $R_{\text {rad }}$; therefore, the flame in the presence of $\mathrm{He}$ in a microgravity environment is affected by the sample width strongly. When the sample width is $5 \mathrm{~mm}$, the $R_{\text {side }}$ becomes 4 times larger than that at $10 \mathrm{~mm}$ width. This is the reason why the flame spread is not observed in $5 \mathrm{~mm}$ wide with the $\mathrm{He}$ diluent.

According to the scale analysis, the difference in the suppression tendency discussed above resulted from the difference in the flame size in the microgravity regime. Hence, we measured the preheat zone length, $L_{g}$, in the four diluent conditions. Figure 6 shows the images obtained with the interferometer in the each balance condition $^{18)}$. It can be seen from these images that the preheat zone length for $\mathrm{He}$ is much larger than those at other conditions, even in relatively fast ambient flow. This result is consistent with the fact that very weak flame is observed with $\mathrm{He}$ as the diluent. On the other hand, in the $\mathrm{CO}_{2}$ balance condition, the preheat zone length is smallest of the four conditions. Additionally, the length in $16 \mathrm{~cm} / \mathrm{s}$ flow and that in a quiescent condition are almost the same, which is consistent with the fact that the robust flame is observed with $\mathrm{CO}_{2}$ as the diluent.

\section{Conclusions}

The flame spread rate in microgravity has been investigated with changing the diluent gas and the sample width in order to separate the radiative effects from the three dimensional side losses. Experimental results from drop tower experiments along are supported by a scale analysis to explore the relative significance of the two types of heat losses. It is found that the mechanism of the flame spread suppression in microgravity is quite different when diluents are switched. With He as the diluent, the conductive heat loss to the side direction is the dominant factor, and the flame spread is suppressed strongly when the sample width is narrow. In all other situations, the radiative loss is the dominant factor for the suppression. This difference is linked to the difference in the preheat zone length in microgravity regime. For He, the flame becomes very weak and sensitive to the sample width and the ambient flow velocity, whereas in the thermal regime (downward spread in normal gravity), the results is just the opposite with He providing the fastest environment for flame spread. In the other extreme, when the diluents is $\mathrm{CO}_{2}$, the flame exhibits low sensitivity to both the ambient flow velocity and the sample width, even showing robustness in a quiescent condition. These experimental results are consistent with the prediction of the scale analysis.

\section{Acknowledgements}

This study is funded by a part of Ground Research for Space Utilization promoted by Japan Space Forum. We also gratefully acknowledge support from NSF through the CyberInfrastructure CI-TEAM Grant 0753283.

\section{References}

1) Bhattacharjee, S. Artenkirch, R. A.: Radiation-Controlled, Opposed-Flow Flame Spread in a Microgravity Environment, Proc. Combust. Inst., 23 (1990), pp. 1627-1633.

2) Bhattacharjee, S. Artenkirch, R. A., and Sacksteder, K.: The Effect of Ambient Pressure on Flame Spread over Thin Cellulosic Fuels in a Quiescent , Microgravity Environment, $J$. Heat Transfer, 118 (1996), pp.181-190.

3) Ramachandra, P. A., Altenkiech, R. A., Bhattacharjee, S., Tang, L., Sacksteder, K., and Wolverton, M. K.: The Behavior of Flames Spreading over Thin Solids in Microgravity, Combust. Flame, 100 (1995), pp. 71-84.

4) Kushida, G., Baum, H. R., Kashiwagi, T., di Blasi, C.: Hea and Mass Transport From Thermally Degrading Thin Cellulosic Materials in a Microgravity Environment, J. Heat Transfer, 114 (1992), pp.494-502.

5) McGrattan, K. B., Kashiwagi, T., Baum, H. R., and Olson, S. L.: Effects of Ignition and Wind on the Transition to Flame Spread in a Microgravity Environment, Combust. Flame, 106 (1996), pp. 377-391.

6) Kashiwagi, T., McGrattan, K. B., Olson, S. L., Fujita, O., Kikuchi, M., and Ito, K.: Effects of Slow Wind on Localized Radiative Ignition and Transition to Flame Spread in Microgravity, Proc. Combust. Inst., 26 (1996), pp. 1345-1352.

7) Takahashi, S., Kondou, M., Wakai, K., and Bhattacharjee, S.: Effect of Radiation Loss on Flame Spread over a Thin PMMA Sheet in Microgravity, Proc. Combust Inst., 29 (2002), pp. 2579-2586.

8) Honda, L., and Ronney, P. D.: Effect of Ambient Atmosphere on Flame Spread at Microgravity, Combust. Science Technology, 133 (1998), pp. 267-291.

9) Son, Y. and Ronney, P. D.: Radiation-Driven Flame Spread over Thermally Thick Fuels in Quiescent Microgravity Environments, Proc. Combust. Inst., 29 (2002), pp. 2587-2594.

10) Kumar, A., Shih, H. Y., T'ien, J. S.: A Comparison of Extinction Limits and Spreading Rates in Opposed and Concurrent Spreading Flames over Thin Solids, Combust. 
Flame, 132 (2003), pp. 667-677.

11) Takahashi, S., Nagumo, T., Wakai, K. and Bhattacharjee, S.: Effects of Ambient Condition on Flame Spread over a Thin PMMA Sheet, JSME International Journal B, 43 (2000), pp. 556-562.

12) Bhattacharjee, S., Wakai, K., and Takahashi, S.: Predictions of a Critical Fuel Thickness for Flame Extinction in a Quiescent Microgravity Environment, Combust. Flame, 132, pp. 523-532.

13) Rybanin, S.: The Structure and Spread Limits of a Diffusion Flame over This Solid Fuel, Proc. Combust. Inst., 27 (1998), pp. 2791-2796.

14) Mell, W.E., Kashiwagi, T.: Effects of Finite Sample Width on Transition and Flame Spread in Microgravity, Proc. Combust Inst., 28 (2000), pp. 2785-2792.

15) Mell, W. E., Olson, S. L., and Kashiwagi, T.: Flame Spread along Free Edges of Thermally Thin Samples in Microgravity, Proc. Combust Inst., 28 (2000), pp. 2843-2849.

16) Bhattachrjee, S., West, J., Dockter, S.: A Simplified Theory for de Ris Flame over Thin and Thick Fuels, Combust. Flame, 104 (1996), pp. 66-80.

17) de Ris, J. N.: Spread of a Laminar Diffusion Flame, Proc. Combust. Inst., 12 (1969), pp. 241-255.

18) Takahashi, S., Bhattacharjee, S., Ihara, T., and Wakai, K.: Effect of Ambient Gas on Flame Spread over a Solid Material in Microgravity, J. Jpn. Soc. Microgravity Appl., 24 (2007), pp.225-230. 